of the scientific spirit as opposed to the hope may say that it is contrary to our habit to to spend money on matters relating to peace; that wa dangers are the only ones to be met or to be studied. out of the question. Every scientific advance is now, and will in the future be more and more, applied to scientific corps; it is a question of an armed force scientific from top to bottom. Thank God, the navy
has already found this out. Science will ultimately both of peace and war, and must both have a Already it is not looking too far ahead to see that in a perfect state there will be a double use of each citiadvances, the more the old difference between the peaceful citizen and the man at arms will disappear
The barrack, if it still exists, and the workshop will be assimilated; the land unit, like the battleship, will become a school of applied science, self-contained, in not think it is yet recognized how much the problem that with which we are now chiefly concerned.

These, then, are some of the reasons which compel
me to point out that a scientific council, which migh ing a scientific committee of the Privy Council, in dealing primarily with the national needs in times To sum up, then. My earnest appeal to you is to gird up your loins and see to it that the science of the have endeavored to point out to you how the nation at present suffers from the absence of a powerful, con-
tinuous, reasoned expression of scientific opinion, urging in season and out of season that we shall be armed as other nations are with efficient universities an
facilities for research to uphold the flag of Britain in facilities for research to uphold the flag of Britain in
the domain of learning and discovery, and what they

I have also endeavored to show how, when this is
done, the nation will still be less strong than it need be if there be not added to our many existing councils another, to secure that even during peace the benefits nation's interest can bring shall not be neglected a they are at present. Lest some of you may think that
the scientific organization which I trust you will determine to found would risk success in working on such late Prince Consort occupied this chair, he referred to "impediments" to scientific progress, and said, "they
are often such as can only be sucessfully dealt with
by the powerful arm of the state or the long purse of
the nation." If the Prince Consort had lived to conthe nation." If the Prince Consort had lived to con tinue his advocacy of science, our position to-day would for Britain as the loss of a great campaign. If we mend.

I have done what I feel to be my duty in bringing the present condition of things before you. It is now
your duty, if you agree with me, to see that it be put
right. You can if you will.

\section{THEORIES OF SLEEP}

By Percy G. Stiles, University and Bellevue Hospital IT is not easy to define the condition of sleep in readily recognize the states of rest and activity, but where the element of consciousness must be considered we are at once upon uncertain ground. If we trasted with waking, we do well to limit our use of
the word to the case of man and the most intelligent the word to the case of man and the most intelligen
animals. Sleep in this sense is only to be associated with highly developed nervous systems and its final explanation is to be sought in events taking place in Ve brain.

Various writers upon the subject of sleep have matter. Some have undertaken to show why there is the need of sleep and why the tendency to sleep comes
on at the close of each day. These writers have dealt with general or systematic causes. Others have con-
cerned themselves with the cause of the unconscious cerned themselves with the cause of the unconscious
- -r dreaming - state in which the sleeper lies. They Since the several theories are thus distinct in their application they are not necessarily mutually exclusive.
Broadly speaking, we feel sure that the need of sleep follows from general or iocal fatigue. During waking hours the decomposition processes of the body doubt-
less rise above the life-long mean, and sooner or later there must be a compensatory fall below the
average. The adaptation of the race to alternating average. The adaptation of the race to alternating

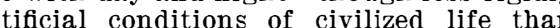
in more primitive times.

Fatigue at bottom is a chemical phenomenon, and
so the theories of the first class are chemical. When a so the theories of the first class are chemical. When a
muscle has been stimulated until it exhibits the wellknown signs of fatigue, there are two possible insubstances or an accumulation of poisonous waste. chemical changes that lead to sleep. We have had an exhaustion theory advanced by Pflüger and an accuexhaustion theory advanced by $P$
mulation theory offered by Preyer.

Pflüger's theory has little experimental evidence in its favor. We know that a bloodless muscle may be
subjected to a vacuum and made to part with its free oxygen, but that it is still capable of doing much
work and of giving off carbon dioxide. In other words, oxidation may take place in the absence of free oxygen. namely, that there is a store of the element in loose chemical combination. "This store in the cells is
often spoken of as "intra-molecular" oxygen, and its amount may be supposed to vary between
rather wide limits. Pnüger pointed out that during the day, the katabolic processes being above the aver-
age, this hoard might be reduced until the lack of it should lead to the depression of functional activity
and the suspension of consciousness characteristic of sleep.

Perhaps no one will maintain that this theory is adequate by itself. If there were nothing but intrathat a day of idleness would leave one fresh and bright at bed-time and that severe exercise for half Pflüger's idea seems to explain more readily the sen-
sation of being tired than that of being sleepy, which is so often quite independent of the other.

The alternative theory is to the effect that the wasteproducts of metabolism are not fully and promptly removed as they are formed during the day's activities, is induced. The lactic acid produced in muscular con-
tractions is held responsible for a great part of this toxic process. Acidity of the blood produces coma,
and whatever reduces its normal alkalinity might be expected to favor sleep. Many objections to this theory suggest themselves. It does not explain why the onset of sleep is relatively sudden, nor why we are sleepy in the height of digestion when the blood is most alkaline. It is perhaps less easy to assail it if
we suppose that the waste-products in question are not at large in the blood but have accumulated in certain we need not assume a large quantity of these narcotic
poisons, but only a peculiar distribution, and we can see why mental work is quite as fatiguing as physica work. transition from wakefulness to sleep seems
The tron
rather abrupt, but is not instantaneous. Motor control rather abrupt, but is not instantaneous. Motor control agree that of the avenues of communication with the orld without, hearing is the last to be closed. Thi clock or the unwelcome call is heard for an appreciable time before the eyes can be opened or a definite sleep is favored by the removal of all that may excite either the attention or the reflexes. Darkness, quiet, sought. Sleep may be prevented by any of the con-
trary conditions-light, noise, pain or anxiety. When trary conditions-light, noise, pain or anxiety. When lation, such as may be secured by taking a slightly uncomfortable position. Evidently sleep presupposes a release of the brain from many stimuli and may be granted. There is on record the case of an unfortunate eye and deaf in one ear. His mentality was of a low to cover the serviceable eye and ear for a - few moto cover the serviceable eye and ear for a-few modent on an unceasing flow of sensory impulses into the
brain. A person of higher intelligence, similarly af fricted, would doubtless sleep much less readily, for trains of thought
external stimuli.

The approach of sleep is accompanied by distinct vascular changes. The blood stream is shifting its bed. A most imperious summons to sleep conies from ened blood-flow through the tear glands. At the same time the temperature of the skin rises, possibly exthen of a dilatation of the cutaneous vessels as sleep
comes on, and the final passage into unconsciousness is These vascular changes have been nicely gaged by what is known as. the plethysmographic method, where the
subject lay with one hand and forearm fixed in a glass cylinder filled with water. An increase of blood
in the arm displaced water from the cylinder and a delicate recording apparatus showed how this dilatation account of such experiments, of more than technical interest, is that contributed by Dr. W. H. Howell It is generally inferred that the cutaneous dilatation at once reduces the general blood-pressure and the
quantity of blood flowing through the brain, by diverting a large share to the skin. The lowering of
pressure has been demonstrated by Brush and Fayerpressure has been demonstrated by Brush and Fayer-
weather; the fact that there is anemia of the brain tion. An English physiologist, Hill, has been led to believe that the dilatation of blood-vessels that relieves the brain in sleep is not limited to the skin, but shared by the arteries of the digestive tract. That this is so
is difficult to prove, but it is suggestive that a heavy meal is followed by a long sleep in the case of the
lower animals, and often with us by a hard struggle lower animals, and often with us by a hard strugg
with drowsiness. Cerebral anemia may be merely a concomitant of
sleep, but it has frequently been held to be its im-
mediate cause, the cells having previously been fatigued and suffered a lowering of functional capacity
which has made them increasingly susceptible to depressing influences. This is the basis of Howell's the-
ory. He has suggested that the exhaustion of the vasomotor center is what induces sleep. We know that this hold the blood-vessels in a state of constriction greater
than is natural for them. This tonic activity can only mean constant metabolism in the cells of the center. ferent impu, the center is subject to the play of afflexly spurred to action by every sensory impression through eye or ear. It is called to respond in an ap-
propriate manner to every change of posture or other muscular movement. It does not escape the effects
of psychic processes, emotional states. Nothing is more natural than to suppose that the nerve cells of
the center become fatigued by this unceasing activity. After the hours that we habitually number in a period of waking it responds less and less readily to the de-
mands made upon it. It begins to lose its grip, so to speak, on the superficial and perhaps the splanchnic
vessels. The blood supply to the brain tends to become less and the pressure in its arteries to be re-
duced. The subjective consequence is drowsiness. It it is resisted by fixing the attention or by exercise, the
center rallies temporarily under the spurring, contracting the vessels and turning the tide of blood back into
the brain. But the anemia soon returns, and the drowsiness becomes more compelling. When the per-
son lies down, a flood of sensory impulses that have been pouring in from the contracting muscles is suddenly checked. The eyes are closed and the stream
of visual impulses ceases. With the withdrawal of this reflex stimulation and the acquiescence of the will
the center relaxes still further its hold upon the cutaneous vessels, the blood-flow in the brain becomes more reduced, and unconsciousness comes on. During sleep without as the plethysmographic experiments show. operate by turning pack into the brain a sufficient quantity of blood displaced from the contracting vessels of the skin. Such a stimulus must be a strong
one in the first hour or two of sleep, but later a much weaker one will answer. Several physiologists have night, judging of it by the height from which a weight must be dropped that the sound of its fall shall arouse the sleeper. All have agreed that the greatest deptri
of sleep is reached as early as the second hour. Acof sleep is reached as early as the second hour. Ac-
cording to one writer it becomes steadily more shallow second, minor deepening toward morning. Many imply such a second period of comparatively profound What we call natural waking in the morning is usually due to some stimulus from without-light or sleep of midnight. But the stimulus may come from within, as from the state of certain organs or, cur-
iously enough, from the previous resolution to wake at a certain time, which often operates with some-
thing of the compulsion of a hypnotic suggestion Howell supposes that during sleep the nerve-cells of the vaso-motor center are gradually restored to prime
condition and hour by hour become more irritable. So it is easier as time passes to induce the vascular
changes that involve waking. Moreover, the recuperchanges that involve waking. Moreover, the recuperated center resumes something of its normal tonic
activity before consciousness returns, and so the final step is taken with none of that sense of violence that accompanies a sudden waking from sound sleep. The eral times before the waking state is well established. When one is fairly roused, mental activity and the
pouring in of sensory impulses keep him from further napping.

Now what peculiar condition can be conceived to exist in the brain during the period of anemia and un-
consciousness? What microscopical changes may be supposed to mark the transition from wakefulness to sleep? Oddly enough, the two hypotheses which are which has attracted the greater notice, is that of Du-
val. He has suggested that consciousness depends on the contact of cell-processes in the brain whereby ef-
fects are propagated from neurone to neurone. If
sensory impulses are to alter consciousness, there must be a pathway for their passage. If a single synapse on the course of such a pathway is rendered impassable, the message from the sense-organ is lost from con-
scious life. If every sensory path is interrupted at any point between the periphery and the cortex, there must the body. If all motor paths are likewise broken, there can be no voluntary action. If, in the third place, the association paths are also severed, there can be no syn-
thetical processes of thought, no ideation. In short, the brain must lose its individuality by the breaking of consuppose that every synapse in the central nervous system might be snapped, and impassable gaps opened be-
tween the cells wherever one had been wont to influence another, there must be an end of consciousness, for, in utter isolation, these cells could no longer comphysical basis of psychic life. A much more local disruption of connection, limited perhaps to the cortex,
might be sufficient to explain the subjective condition in sleep. At any rate, Duval's view is that the cortical
cells are capable of retracting or extending their processes so as to sever and resume their relation with
neighboring elements. Experimental evidence in sup-
port of this theory is naturally slight. Wiedersheim has described amoboid movements on the part of cells course it is only in such lower forms that the living course it is only in such lower forms that the living val himself suddenly beheaded dogs that were awake and others in anæsthesia and made histological preparations from the brains. He believed he could distin-
guish the sleeping brain by the more contracted and The second histological theory of sleep, which has been said to be quite opposed to the first, is that of the Italian neurologist, Lugaro. Both demand the capability of amoboid movement on the part of the cells. broken their contacts, Lugaro supposes that they have thought this view seems unreasonable. A multiplicity of contacts and added pathways in the brain might be supposed to imply a richer and keener consciousness. the indiscriminate combination had gone a step further mental confusion might be expected. then fantas ories-practically a state of dreaming. Let the cells commingle their impulses still more freely and con-
sciousness will be lost, for the diffusion of energy in sciousness will be lost, for the diffusion of energy in
the brain will result in a lessened intensity of flow in the principal channels. If each cell scatters its effect in consciousness is to be looked for. According to Duval, the cells which are affected in sleep can not
discharge; according to Lugaro, they may do so, but 
the resulting impulses are utterly dissipated in a maze of by-ways. Waking, according to Duval, is the to Lugaro, it is the restriction of intercourse to habitual and purposeful channels.

There is no reason why we may not be eclectic in regard to these two points of view. It may be that many paths are interrupted in sleep, while others are opened. In the hypnotic state it is clear that man paths are blocked, including those by which the will of the subject habitually asserts itself, while others, ditory la those making connections between the auditory and motor areas, transmit impulses with exwe suppose that certain synapses are broken, as Duval with intensified energy through the narrowed outlet remaining-an idea borrowed from Lugaro. If we consider that a man is most thoroughly awake when hi attention is most rigidly concentrated, when he is man of one idea," we shall perhaps incline towar fugaro's conception of sleep, which is certainly a Hypnosis is accompanied by cerebral congestion an natural sleep by anemia. There is accordingly a stron temptation to suppose that the cell-changes in the two states are opposite in their nature, that in hypnosi the retraction of the dendrites is characteristic, and in natural sleep their extension. The sluggish condition fanciful flights in dreaming falls happily in line with this view. But such speculation is premature. It was said at the outset that the several theories of sleep are not all mutually exclusive. It is possible to go beyond this statement, for we may assign a place to each of those mentioned without inconsistency. We
may suppose in the first place that the alternation of may suppose in the first place that the alternation of rhythm upon the race, so that it is hard for the individual to break from the habitual course in which activity is associated with light and rest with darkness. In other words, the amount of the metabolism tends to keep above a mean for some hours and then to fall below it. The excess of destructive processes over those which are recuperative during the walking
hours results in general and local fatigue, a condition hours results in general and local fatigue, a condition
into which may enter both the depletion of intramolecular oxygen and the accumulation of toxic wasteproducts bocts as a whole the loss of condition a ect to its own peculiar drains. It is very probably the hard-worked vasomotor center which proves to be the vulnerable spot. With its release of the blood-ves-
sels in certain areas from its reinforcing influence sels in certain areas from its reinforcing influence
comes the cerebral anemia. Then, we may suppose comes the cerebral anemia. Then, we may suppoin which has its full supply of blood, that they cease to gaps have opened or because such impulses as do arise are permitted to stray and be scattered, producing no
effect in consciousness or one which is quite bizarre and meaningless.

Such an outline as this is a composite scheme in which the conditions emphasized by Pfluiger and Preye Howell's idea is accepted as explaining well its sleep, its varying depth and the awakening, while the pictures sketched by Duval and Lugaro are combined to represent the intimate state of the slumbering brain.-Popular Science Monthly.

MANUFACTURE OF STAMPED ENVELOPES.*

THE envelope machine used by the United States government was invented by $\mathrm{Mr}$. Horace J. Wickham of Hartford, Conn. It gums, stamps, prints, folds, is placed upon the top of the table or bed, which elevates them to the proper height for the pickers. Above the blanks is a gum box, containing rollers to take

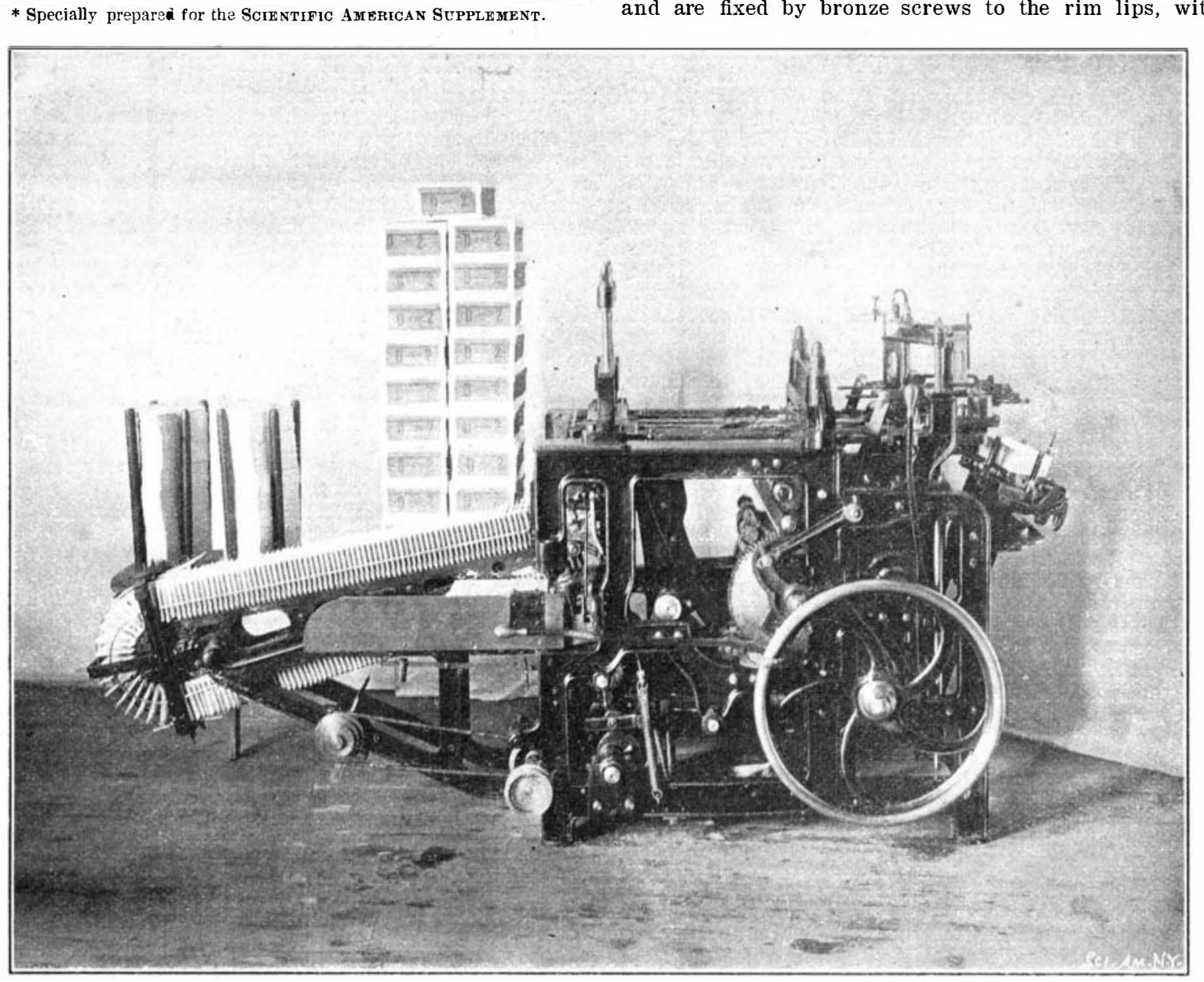

THE WICKHAM ENVELOPE MACHINE to separate and rise in position to be taken by th facture to a very low figure.

\section{JENATZY MAGNETIC CLUTCH.}

M. Camille Jenatzy, winner of the late Gordon lately been patented abroad and in this country, an $A$ is the motor shaft, $B$ the

wheel rim and $D$ the driven shaft hub, $C$ the flyof $D$, which is squared, slides a sleeve, $F$, backed by a led to an insulated feeding ring, $K$, as shown. not wholly clear from the specifications, but apparently the two concentric rings, $L M$, are of soft iron

and are fixed by bronze screws to the rim hips, with the gum and spread it on pickers, causing the top blank pickers, which rise and fall, thus causing the top
blank to separate and rise in position for the con veyers. The latter carry the blanks forward over the die and type, where inks of the proper colors are sup plied. After being stamped and printed they pass on gether and the fourth being left to dry. The envelope is then dropped into an endless chain from which, by means of pincers, they are pulled out from the side, one by one, the machine counting them in to package
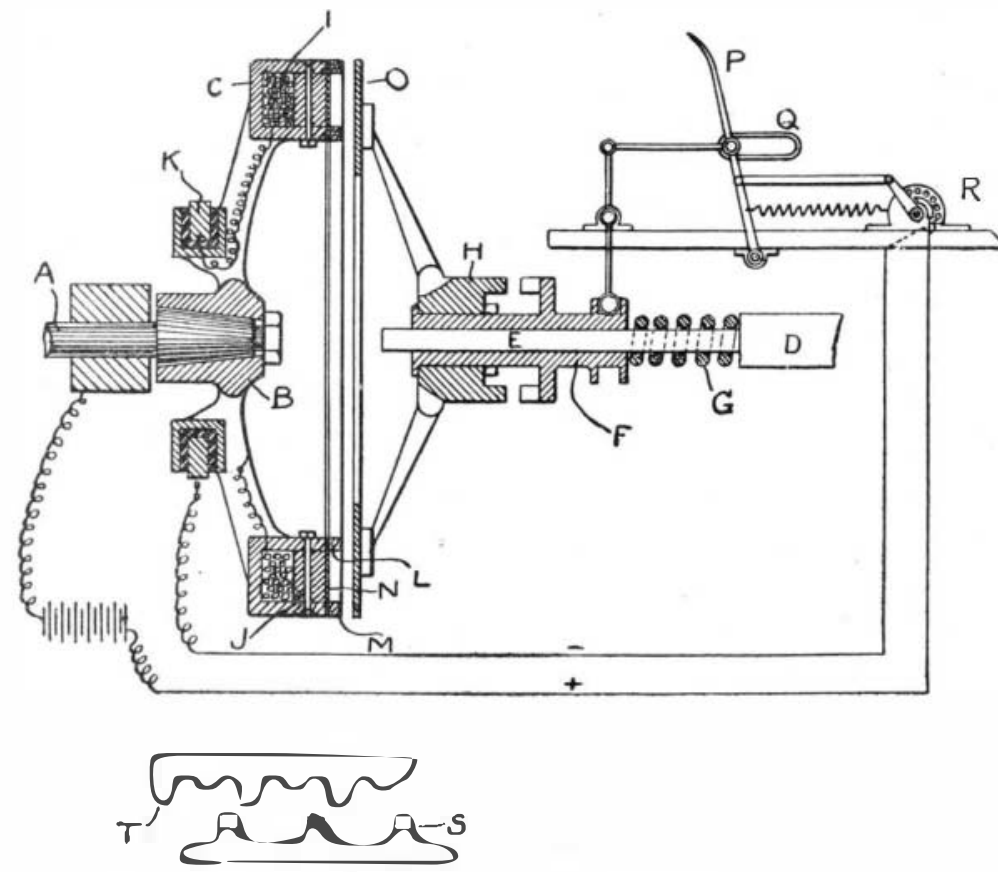

THE JENATZY MAGNETIC FLYWHEEL CLUTCH.

ng. This machine was designed and especially built extent in manufacturing for the is used to quite an chine, with one attendant, turns out forty-five thousand envelopes a day, thus reducing the cost of manuBennett race and previously well known as the de signer of the "Jamais Contente" and other electric
vehicles, is the inventor of a magnetic flywheel clutch which is successfully used on the Belgian "Pipe" cars, Mercedes and Mor's cars next year. This clutch has rom a comparison of the specifications the following spring, $G$, and carrying loosely on it the hub, $H$, of
the driven member of the clutch. The rim, $C$, is made an electro-magnet by recessing it, leaving an inner and an outer lip to form the poles, and imbedding the
coil, $I$, between them. A follower ring, $J$, of nonmagnetic metal is then bolted in place. One terminal magnetic metal is then bolted in place. One terminal
of the coils is grounded on the flywheel and the other

The remaining construction of the rim portion is and are fixed by bronze screws to the rim lips, with

\section{impact} impact, and receive some of the change of velocity in
that way before they settle in to final mesh. The ob-
ject of the short teeth would then be simply to prevent
"backlash"" when the teeth are finally engaged.-The
Automobile.

PRODUCTION OF COKE IN 1902

'THE production of coke in the United States in 1902, according to the report now in press prepared by Mr. E. W. Parker for the United States Geological Survey, which includes any year in our history. The product, ovens, amounted the output from retort or by-product compared with $21,795,883$ short tons in 1901 , and with $20,533,348$ tons in 1900 . The increase in 1902
over 1901 amounted to $3,605,847$ short tons, or 16.5 per cent, and this increase would have been murh larg. with the demand for coke and with the productive capacity of the ovens. The unprecedented production of coke in 1902 was accompanied by an increase of value which was even more worthy of note. The average price per ton at the
ovens was the highest recorded in a period of 23 years, and the total value reached the high figure of $\$ 63,339$, or 42.5 per cent. The value of the coal used in the manufacture of coke in 1902 exceeded that of 1901 by $\$ 7,922,563$, from which it appears that the value of the coke product increased $\$ 10,970,681$ over and above the
increased value of the coal used in its production. In 1901 the highest price obained for Connellsville furnace coke was $\$ 4.25$, which was paid in March and April of that year. In September and october of 1902 , ton, consumers were paying from $\$ 10$ to $\$ 12$ per ton for prompt delivery, and as much as $\$ 15$ per ton was re During 1902 there were 69,069 coke ovens in existence in the United States, as compared with 63,951 ive and produced an average of 378.4 tons per oven.
The total number in 1902 included 1,663 by-product 